\title{
Direct evidence for two different neural mechanisms for reading familiar and unfamiliar words: an intra-cerebral EEG study
}

\section{Alexandra Juphard ${ }^{1 \dagger}$, Juan R. Vidal ${ }^{2,3+}{ }^{\dagger}$,Marcela Perrone-Bertolotti ${ }^{4}$, Lorella Minotti ${ }^{5,6}$, Philippe Kahane ${ }^{5,6}$, Jean-Philippe Lachaux ${ }^{2,3}$ and Monica Baciü ${ }^{*}$}

${ }^{1}$ CMRR and Neuropsychologie, Département de Neurologie, CHU de Grenoble, Grenoble, France

2 Brain Dynamics and Cognition Team, Lyon Neuroscience Research Center, INSERM U1028, CNRS, UMR 5292, Lyon, France

${ }^{3}$ Université Claude Bernard, Lyon 1, Lyon, France

${ }^{4}$ Laboratoire de Psychologie et NeuroCognition, UMR 5105 CNRS Université Pierre Mendès-France, Grenoble, France

${ }^{5}$ Neurology Department, Grenoble Hospital, Grenoble, France

${ }^{6}$ INSERM U836, Grenoble Institute of Neurosciences, Grenoble, France

\section{Edited by:}

Hans-Jochen Heinze, University of Magdeburg, Germany

Reviewed by:

Ruthger Righart, Institute for Stroke and Dementia Research, Germany

Thomas Gruber, University of

Osnabrueck, Germany

*Correspondence:

Monica Baciu, Laboratoire de Psychologie et NeuroCognition, UMR 5105, CNRS, Université Pierre Mendès France, BP47, 38040

Grenoble Cedex 9, France.

e-mail: mbaciu@upmf-grenoble.fr

${ }^{\dagger}$ Alexandra Juphard and Juan R. Vidal have contributed equally to this work.
After intensive practice, unfamiliar letter strings become familiar words and reading speed increases strikingly from a slow processing to a fast and with more global recognition of words. While this effect has been well documented at the behavioral level, its neural underpinnings are still unclear. The question is how the brain modulates the activity of the reading network according to the novelty of the items. Several models have proposed that familiar and unfamiliar words are not processed by separate networks but rather by common regions operating differently according to familiarity. This hypothesis has proved difficult to test at the neural level because the effects of familiarity and length on reading occur (a) on a millisecond scale, shorter than the resolution of $\mathrm{fMRI}$ and (b) in regions which cannot be isolated with non-invasive EEG or MEG. We overcame these limitations by using invasive intra-cerebral EEG recording in epileptic patients. Neural activity (gamma-band responses, between 50 and $150 \mathrm{~Hz}$ ) was measured in three major nodes of reading network - left inferior frontal, supramarginal, and inferior temporo-occipital cortices - while patients silently read familiar (words) and unfamiliar (pseudo-words) items of two lengths (short composed of one-syllable vs. long composed of three-syllables). While all items elicited strong neural responses in the three regions, we found that the duration of the neural response increases with length only for pseudo-words, in direct relation to orthographic-to-phonological conversion. Our results validate at the neural level the hypothesis that all words are processed by a common network operating more or less efficiently depending on words' novelty.

Keywords: intra-cerebral, iEEG, gamma-band, GBR, familiarity, epilepsy, reading, word

\section{INTRODUCTION}

During reading, eyes browse through sentence elements at a very fast pace of around five fixations per second on average (Kliegl et al., 2006). Current models propose that such reading speed is due to efficient neural mechanisms able to process familiar words globally (Coltheart et al., 1993, 2001; Ans et al., 1998; Perry et al., 2007). By definition, such global processing would allow for fast semantic and phonological analysis independently of word length. After intensive practice, as unfamiliar letter strings (novel, unfamiliar words) become familiar, reading speed would increase strikingly from slow sequential to fast and more global reading and recognition. Indeed, several behavioral studies have shown that naming latency, a proxy of reading time, increases with length for unknown or unfamiliar words such as pseudo-words but not for familiar words (Mason, 1978; Weekes, 1997; Ans et al., 1998; Ferrand, 2000; Ferrand and New, 2003; Juphard et al., 2004, 2006; Valdois et al., 2006). The neural substrate of this transition from sequential to global processing is still unclear. At least two scenarios can be envisioned: (i) brain regions supporting familiar and unfamiliar words reading - i.e., supporting orthographicto-phonological conversion (print-to-sound), phonological, and semantic analyses - would be the same but their responses would decrease in duration as familiarity increases (ii) familiar and unfamiliar words would be processed by separate brain networks operating at different speeds.

Functional MRI results are more consistent with the first scenario. Several fMRI studies (Baciu et al., 2002, 2005; Valdois et al., 2006; Juphard et al., 2008) have shown stronger BOLD responses to long vs. short pseudo-words, but not to long vs. short familiar words in several nodes of the reading network, such as Broca's area (Broca), the supramarginal gyrus (SMG), and the fusiform wordform area within the inferior occipito-temporal cortex (IOTC). However, the time resolution of fMRI is not sufficient to demonstrate unambiguously an effect of syllabic length on the duration of neural responses. Since the only non-invasive brain recording techniques with high-temporal resolution (EEG and MEG) lack the spatial precision to isolate responses from individual components of the reading network, we turned to invasive EEG recordings. 
We collaborated with five epileptic patients undergoing invasive pre-surgical intra-cerebral EEG (iEEG) to measure neural activity with millimeter and millisecond resolution in the reading network. The present study focuses on three crucial nodes of that network (Fiez and Petersen, 1998; Vigneau et al., 2006): the inferior frontal gyrus (Broca's area, BA 44/45), the SMG (BA 40), and the inferior temporo-occipital cortex (ITOC, BA 37/19).

While iEEG is primarily used to differentiate epileptogenic from healthy cortical tissues, task-induced energy modulations of iEEG signals in the gamma-band $(50-150 \mathrm{~Hz}$; gamma-band responses, GBR), have become increasingly popular to reveal the fine dynamics of neural activity underlying complex stimulus processing (Vidal et al., 2010), cognition in general (Jerbi et al., 2009), and reading in particular (Mainy et al., 2008). Lachaux et al. (2007) combined fMRI and intra-cranial EEG recordings of the same epileptic patients during a semantic decision task and found a close spatial correspondence between regions of fMRI activations and recording sites showing EEG energy modulations in the gamma range $(>40 \mathrm{~Hz})$. These findings further support previous findings that gamma-band modulations co-localize with BOLD variations and also indicate that fMRI may be used as a constraint to improve source reconstruction of gamma-band EEG responses. The authors used a semantic task (living-non-living categorization) which is different from a simple reading task mainly based on word recognition, used in the present study. If both tasks (reading and semantic categorization) operate with similar items, words, the attention is focused differently according to required processes: finding semantic representations, classification, and decision making for semantic task; grapheme-to-phoneme conversions phonological storage and articulatory output for reading. Consequently, although the processes and regions revealed by these two tasks are partially overlapped, they are also distinct. Reading network explored by Lachaux et al. (2007) is larger as is related to semantic representations of words. The reading network explored in this study is supposed to be narrower and more specific to the process of word recognition.

In addition, GBR have recently been shown to correlate tightly with the average firing rate of neural populations (Ray and Maunsell, 2011).

We measured the amplitude and duration of GBR elicited by familiar (words) and unfamiliar (pseudo-words) letter strings, as a function of syllabic length (short vs. long items). We found that all items elicited clear neural responses in all three regions of interest (Broca, SMG, and ITOC), but the duration of the neural responses increased with length only for pseudo-words. Our results provide an explanation at the neural level for the increase in reading speed with word familiarity. The same brain regions process familiar words globally and unfamiliar words sequentially.

\section{MATERIALS AND METHODS EPILEPTIC PATIENTS}

Five epileptic patients (P1-P5) suffered from drug-resistant partial epilepsy and were candidates for surgery in order to remove the epileptic region. There were four female patients and one male patient; all were right-handed native French speakers and aged from 33 to 55 years (mean of age 44 years). MRI revealed a left hippocampal sclerosis in four patients and no lesion in the remaining patient. All demographic data are shown in Table A1 in Appendix.

\section{ELECTRODES IMPLANTATION IN EPILEPTIC PATIENTS}

The implantation sites were selected entirely for clinical purpose with no reference to the present experimental protocol. However, the patients who entered this protocol were selected because their implantation sampled regions classically associated with language and reading (peri-sylvian regions). Eleven to 14 semi-rigid electrodes were implanted per patient, in cortical areas which varied depending on the suspected origin of seizures. Across patients there were no recording sites at the exact same anatomical location. A total number of 344 sites were recorded from the five patients, 310 in the left hemisphere, and 34 in the right. Each electrode had a diameter of $0.8 \mathrm{~mm}$ and comprised 10 or 15 leads of $2 \mathrm{~mm}$ length, $1.5 \mathrm{~mm}$ apart (Dixi, Besançon, France), depending on the target region. Therefore, various medial and lateral cortical areas were evaluated, including sulcal cortex. It has been shown that the essential regions for language are located along Sylvian fissure/sulcus (Ojemann et al., 1989). The electrode contacts were identified on each individual stereotactic scheme and then anatomically localized, using the proportional atlas of Talairach and Tournoux (1988). In addition, the computerassisted matching of post-implantation CT-scan with 3-D MRI pre-implantation, provided direct visualization of the electrode contacts with respect to the brain anatomy of each patient (Actavis, Lyon, France). The patients performed the task a few days after the implantation of the electrodes and all of them have previously given their informed consent to participate in the experiment. In this study we analyzed six recording sites located in three regions of interest: Broca precentral (patients 2 and 4), supramarginalis gyrus (patients 1 and 3), and inferior occipital-temporal cortex (patients 1 and 5).

\section{STIMULI}

Stimuli were 208 French words and 208 pronounceable pseudowords (for each lexical type, 104 short, mono-syllabic, and 104 long, three-syllabic). They were selected from BRULEX lexical database for French (Content et al., 1990) and were low to high frequency. Moreover, they were closely matched on frequencies. For short words the mean frequency (occurrence per one million) was 3234.6 $(\mathrm{SD}=4962.1$; range $=46-21769)$. For long words the mean frequency was $3152.9(\mathrm{SD}=4373.6$; range $=68-21756)$. The short pseudo-words were created by recombining the onset, nucleus, and coda of short words; long pseudo-words were generated by recombining the syllables of long words. For each length, words and pseudo-words were matched in terms of number of letters. Half of short items were five and the other half were six letters length. Half of long items were eight and the other half were nine letters length. Furthermore, words and pseudo-words were matched on onsets in order to control for acoustic factors that could bias the triggering of the vocal key (Kessler et al., 2002). Words and pseudo-words had no neighbors in order to prevent from a potential effect of this variable on reading latencies (Andrews, 1997). To resume, four experimental conditions were evaluated: "Short words" (words composed of one-syllable, i.e., Word 1); "Long words" (three-syllables, i.e., Word 3); "Short pseudo-words" (one-syllable, i.e., Pseudo-word 1), "Long pseudowords" (three-syllables, i.e., Pseudo-word 3). Three lists of stimuli were presented - two composed of 144 items ( 72 words) each and a third one composed of 128 items (64 words). The conditions were 
randomly presented in each list. The order of list presentation was counterbalanced across participants.

\section{BEHAVIORAL PRE-TEST OF STIMULI IN HEALTHY SUBJECTS}

Before iEEG recording in patients, a behavioral experiment was conducted in healthy subjects in order to pre-test the stimuli. A control group of 22 right-handed native speakers of French was examined. They were placed in front of a computer (Dell PC) monitor and visualized the stimuli described above delivered by means of E-prime software. The stimuli were presented one at a time on the center of the screen during $500 \mathrm{~ms}$ and separated by a $150 \mathrm{~ms}$ fixation cross. Participants were instructed to read aloud, as accurately and as quickly as possible, each item. The responses were recorded by means of a microphone connected to a voice key. A white screen displayed for $1000 \mathrm{~ms}$ before the next stimulus allowed the experimenter to check naming accuracy by pressing a keyboard button. An ANOVA analysis was used for statistical analysis. To avoid outliers, reaction times (RTs) more than two SD above or below the mean were discarded. The mean reaction times $(\mathrm{mRT})$ and the error rates by-participants (F1) and by-items (F2) for correct responses only, were analyzed by using $2 \times 2$ ANOVAs. Lexicality (word, pseudo-word) and Length (short; long) were within-participant factors in the analysis by-participants (F1) and they were no repeated measure factors in the by-items analysis (F2).

\section{INTRA-CEREBRAL EEG DATA ACQUISITION IN EPILEPTIC PATIENTS}

Intra-cerebral EEG recordings were performed while patients silently read words and pseudo-words. Each of these lists was presented in an individual run and the experiment itself consisted of three runs. The order of presentation was counterbalanced between runs. Patients could take a short break and relax between runs. Stimuli were delivered by means of Presentation software
(Presentation, Neurobehavioral systems) on a Dell PC with a $17^{\prime \prime}$ color monitor. They were written in white lowercase letters (bold Courier new 18) on a light gray background. Each item was presented for $1000 \mathrm{~ms}$ with $1000 \mathrm{~ms}$ inter-stimulus interval (see Figure 1A for experimental design). A fixation cross was presented between stimuli on the center of the screen. Participants were instructed to read each item silently (covert speech).

\section{INTRA-CEREBRAL EEG RECORDING}

Intra-cerebral EEG signals were recorded using an audio-videoEEG monitoring system (Micromed, Treviso, Italy), which allowed the simultaneous recording of 63 depth-EEG channels sampled at $512 \mathrm{~Hz}(0.1-200 \mathrm{~Hz}$ bandwidth] during the experimental paradigm. One of the contact sites in the white matter was chosen as reference. This reference has the same impedance as the other contact sites and was located in a region with no or little source of electrical field. Additionally, the reference was not contaminated by eye-movement artifacts or electromyographic activity from subtle muscle contractions. However, all signals were re-referenced to their nearest neighbor on the same electrode, $3.5 \mathrm{~mm}$ away before analysis (bipolar montage). This method delivers a 5-mm spatial resolution of the signal. We have shown an example of signal resolution with this method in Figure A4 in Appendix. All epileptiform activities were excluded from further analysis. Figure 1C illustrates the global cortical area covered by the electrode implantations across patients.

\section{INTRA-CEREBRAL EEG DATA ANALYSIS Time-frequency analysis}

Intra-cerebral EEG signals were analyzed with the software package for electrophysiological analysis (ELAN-Pack) developed in the INSERM U1028 laboratory (Aguera et al., 2011). We used two methods in order to optimally assess spectral responses and their

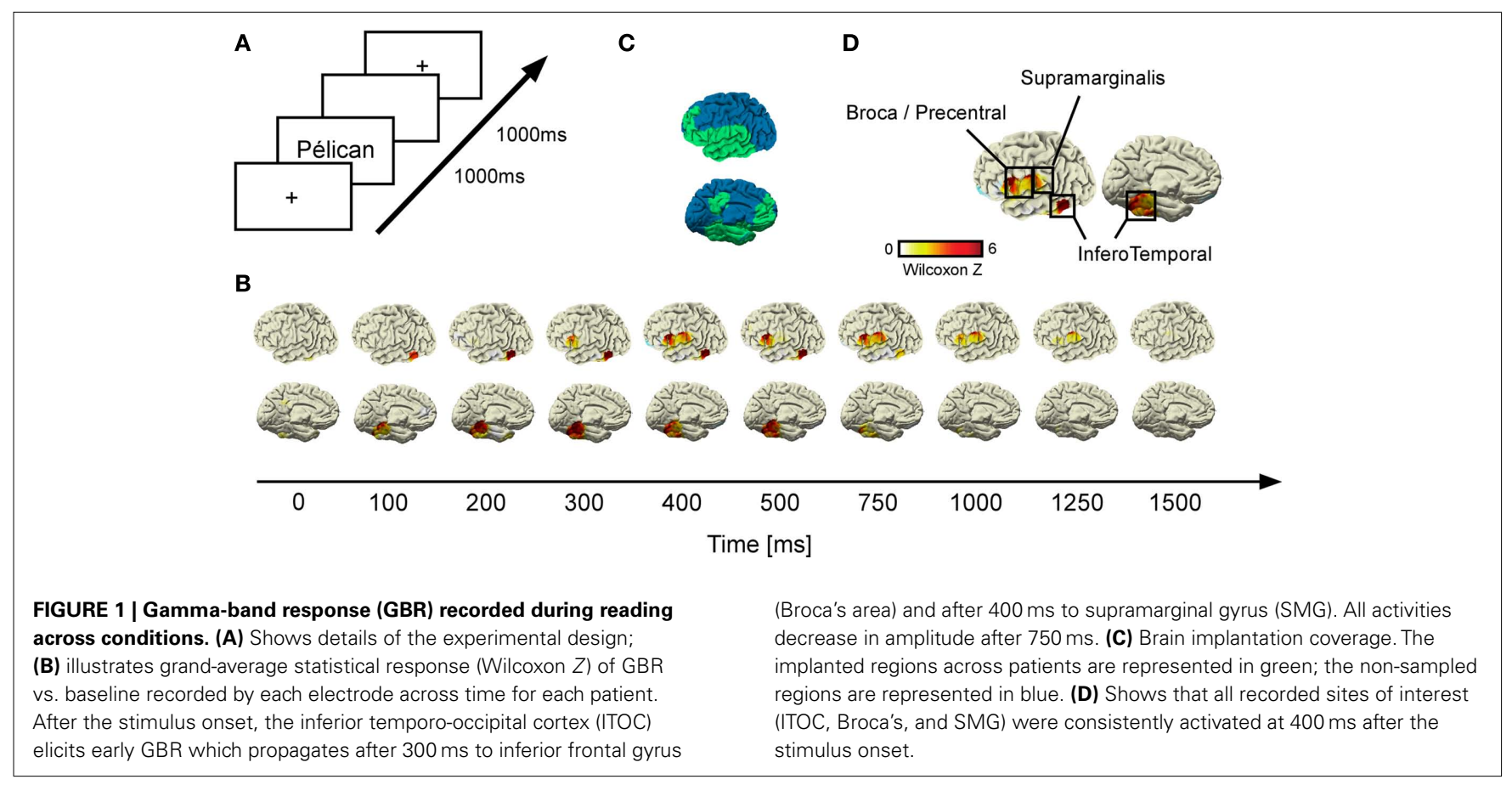


statistical evaluation. First we used the wavelet analysis to delineate a frequency range of interest. We further used the Hilbert transform to obtain the instantaneous amplitude of this frequency band-limited spectral response, which is a less complex signal than the time-frequency (TF) representation, and thus presents higher power for statistical comparisons. For a comparison of Wavelet decomposition and Hilbert transform see Le van Quyen et al. (2001). To show that the two methods obtain similar results we show an example of gamma-band activity with each one of them (Figure A3 in Appendix). Here we first develop the wavelet analysis.

For each single trial, bipolar derivations computed between adjacent electrode contacts were analyzed in the TF domain by convolution with complex Gaussian Morlet's wavelets (TallonBaudry et al., 1997) thus providing a TF power map $p(t, f)=\mid w(t$, $f)\left(\left.s(t)\right|^{2}\right.$, where $\mathrm{w}(t, f)$ was for each time $t$ and frequency $f$ a complex Morlet's wavelet $w(t, f)=A \exp \left(-t^{2} / 2 \sigma_{t}^{2}\right) \cdot \exp (2 i \pi f t)$, with $A=\left(\sigma_{t} \sqrt{\pi}\right)^{(-1 / 2)}$ and $\sigma_{t}=1 /\left(2 \pi \sigma_{f}\right)$ and $\sigma_{f}$ a function of the frequency $f: \sigma_{f}=f / 7$. Significant spectral modulations caused by the stimuli were detected using a Wilcoxon non-parametric test which compared across the trials, the total energy in a given TF tile of the post-stimulus interval (from 0 to $1500 \mathrm{~ms}$ ), with that of a tile of similar frequency extent, but covering a prestimulus baseline period (from -300 to $-100 \mathrm{~ms}$ ) (typically in this study, the frequency extent of the tiles was $1-200 \mathrm{~Hz}$ to detect GBR). Significant responses were defined by $p$-values less than 0.001. Comparison between TF responses measured in different conditions (e.g., response to long pseudo-words vs. response to short pseudo-words) were done by using KruskalWallis non-parametric analysis. It was applied on the raw TF values of energy, on a set of TF tiles $(100 \mathrm{~ms} \times 30 \mathrm{~Hz})$ covering a $(0: 2000 \mathrm{~ms}) \times(5: 200 \mathrm{~Hz})$ domain (one test per tile comparing the values obtained for all the trials in the two conditions).

\section{Hilbert transform analysis}

We used two methods in order to optimally assess spectral responses and their statistical evaluation. First we used the wavelet analysis to delineate a frequency range of interest. The Hilbert transform was used to estimate the global energy in the 50- to $150-\mathrm{Hz}$ range at each sample during the entire recording session in a computationally efficient way. This gamma-band energy time-series could be conveniently processed to measure the mean response to each stimulus category with its SE. For a comparison of Wavelet decomposition and Hilbert transform see Le van Quyen et al. (2001). Here we first develop the wavelet analysis.
To analyze gamma-band activity, continuous sEEG signals were first band-pass filtered in multiple successive $10 \mathrm{~Hz}$-wide frequency bands [e.g., 10 bands from 50 to $150 \mathrm{~Hz}$, such as (50$60 \mathrm{~Hz}),(60-70 \mathrm{~Hz})$, etc]. For the alpha-band $(8-12 \mathrm{~Hz})$ in particular signals were band-pass filtered in that frequency band. Next, for each band-pass filtered signal we computed the envelope using a standard Hilbert transform. Again for each band, this envelope signal (i.e., time-varying amplitude) was divided by its mean across the entire recording session and multiplied by 100 , to express instantaneous amplitude values expressed in percent (\%) of the mean amplitude. Finally, envelope signals computed for each consecutive frequency bands (e.g., eight bands of $10-\mathrm{Hz}$ intervals between 50 and $150 \mathrm{~Hz}$ ) were averaged together, to provide single time-series (high gamma-band envelope) across the entire session. By construction, the mean value of that time-series across the entire recording session is equal to 100 . To test for significant increases or decreases compared to baseline activity, we used paired-sample Wilcoxon signed rank test, followed by false discovery rate (FDR) correction across all time samples. This allowed for quantitative definition of the onset time and duration of activation of specific recording sites. To compare the activity from paired conditions we used the non-parametrical Kruskal-Wallis test followed by FDR correction across all time samples.

\section{RESULTS}

Our main results show that reading familiar (words) and unfamiliar (pseudo-words) items of one-syllable and three-syllables length elicited GBR in the recorded nodes regions (left inferior frontal, SMG, and inferior temporo-occipital cortex). The duration of neural responses increases with length only for pseudo-words. Before presenting in detail the iEEG results, we show first the behavioral results obtained in pre-test in healthy subjects.

\section{BEHAVIORAL RESULTS OF THE PRE-TEST}

The mRT, SD, and mean error rates (\% ER) for reading words and pseudo-words are shown in Table 1.

Behavioral analysis revealed a main effect of Lexicality on naming latencies in the analyses by-participants $[F 1(1,21)=106.39$, $\mathrm{MSE}=1781.21, p<0.00001]$ and by-items $[F 2(1,412)=583.55$, $\mathrm{MSE}=1565.31, p<0.00001]$. The mean RTs was above $90 \mathrm{~ms}$ longer for reading pseudo-words $(M=601.09 \mathrm{~ms})$ than words $(M=508.28 \mathrm{~ms})$. Moreover, the Length interacted with Lexicality in the analyses by-participants $[F 1(1,21)=61.48, \mathrm{MSE}=516.28$, $p<0.00001]$ and by-items $[F 2(1,412)=95.55, \mathrm{MSE}=1565.31$, $p<0.00001]$. The planned comparisons revealed that long pseudo-words yielded significantly longer latencies than short

Table 1 | Behavioral results obtained during pre-test in healthy subjects.

\begin{tabular}{lllll}
\hline & Word 1 & Pseudo-word 1 & Word 3 & Pseudo-word 3 \\
\hline $\mathrm{mRT}(\mathrm{ms})$ & 506.28 & 510.28 & 561.11 & 641.07 \\
$\mathrm{SD}$ & 51 & 51.6 & 71.75 & 97.6 \\
\%ER & 1.55 & 2.72 & 1.84 & 3.98
\end{tabular}

The table resumes the mean reaction time (mRT), the SD and the mean error rate (\% ER) for verbal items according to lexicality (words, pseudo-words), and length (one-syllable, three-syllables). 
pseudo-words $[(F 1(1,21)=67.02, \mathrm{MSE}=1049.51, p<0.00001$; $F 2(1,412)=219.7, \mathrm{MSE}=1565.31, p<0.00001)]$. Naming latencies for short words did not differ from long words $[(F 1(1$, $21)=3.89, \mathrm{MSE}=45.05, p=0.07 ; F 2<1)$ ]. In sum, the results were similar to those previously reported by our group (Ans et al., 1998; Juphard et al., 2004, 2006; Valdois et al., 2006) and by other authors (Mason, 1978; Weekes, 1997; Ferrand, 2000; Ferrand and New, 2003). Specifically, Lexicality interacted with Length; significant effect of Length has been obtained for pseudo-word but not for word reading.

\section{INTRA-CEREBRAL EEG RESULTS}

Time-frequency analysis (Figure 2) revealed transient and focal energy increases in responses to words and pseudo-words in a broad $(50-150 \mathrm{~Hz}$ ] gamma frequency range (Wilcoxon nonparametric comparison with $(-500:-100 \mathrm{~ms}$ ] pre-stimulus period, see Materials and Methods). Such GBR occurred in a limited number of recording sites clustered in regions of the language network including our three regions of interest: Broca's area (BA 44, 45), SMG (BA 40), and ITOC (BA 37/19; Figure 1D and Appendix for Talairach coordinates). As shown in Figure 1B, GBR across patients were elicited initially in inferior temporal cortices, between 100 and $200 \mathrm{~ms}$ after stimulus onset. SMG and Broca's area become activated slightly later $(\sim 300 \mathrm{~ms})$ and lasted until $\sim 1000 \mathrm{~ms}$ post-stimulus onset (Figure 1B).

We compared directly GBR elicited by words and pseudowords in these three regions of interest. As shown in Figure 3 and Figure A2 in Appendix, the time-resolved responses were stronger in amplitude for pseudo-words compared to words. Importantly, stronger responses for pseudo-words compared to words, were independent of the length of items. Consequently, the lexical effect was obtained for the following comparisons: long words vs. Long pseudo-words and Short words vs. Short pseudo-words (c.f., Figure 3). This difference occurred $500 \mathrm{~ms}$ after stimulus onset.

The length has significant effect on GBR (Figure 4 and Figure A3 in Appendix) only for pseudo-words, with one exception (patient 1, ITOC site). The difference occurred $500 \mathrm{~ms}$ after stimulus onset.

We also analyzed the alpha-band responses, which have been shown to decrease with attention, and could inform regarding the implication of attentional modulation on the gamma-band signals (Wyart and Tallon-Baudry, 2008). As shown in Figures A5 and A6 in Appendix only patient 1 shows a small effect for lexicality when comparing alpha-band amplitude time courses. All other patients show no effect neither of lexicality, nor of word length.

The timing of the activation for these three regions was significantly different (all $p<0.05$, FDR corrected; Table 2). The SMG activation seems to be delayed with respect to activation recorded in Broca's and ITOC.

\section{DISCUSSION}

By using iEEG we have shown that the processing time necessary to read words increases with the syllabic length only when they are unfamiliar to the reader. This observation provides, to our knowledge, the first direct evidence at the neural level that the high-processing speed of familiar words is due to a shift of regime within the reading network, from sequential (syllable-by-syllable) to global (all at once) processing, as words become more familiar. This transition - from sequential to global analysis - explains the efficiency of the reading system in expert adult readers: once familiar, long (poly-syllabic) words are processed as quickly as short (mono-syllabic) words.

This effect had often been demonstrated at the behavioral level, but we provide its first direct transcription at the neural level. Our results are consistent with previous fMRI studies showing increased BOLD responses within the reading network for long pseudo-words compared to short ones (Baciu et al., 2002; Valdois et al., 2006; Juphard et al., 2008). However, BOLD signal increases could be interpreted either as stronger or longer neural activations. To disambiguate between those two interpretations, several groups had used the fine temporal resolution of EEG and MEG to measure the duration of the neural responses to words and pseudo-words as a function of syllabic length (Schendan et al., 1998; Assadollahi and Pulvermuller, 2001; Cornelissen et al., 2003; Wydell et al., 2003; Hauk and Pulvermuller, 2004; Hauk et al., 2006). For instance, two MEG studies had reported a length effect on response duration along the left Sylvain fissure: the response duration was stronger for novel items - pseudo-words - than for familiar words (Cornelissen et al., 2003; Wydell et al., 2003). Our results confirm and refine those conclusions by providing the actual duration of neural processing within individual cortical regions of the reading network, especially Broca's area and the SMG, two components of reading network particularly associated with the conversion of written word-forms into their phonological equivalent.

Behavioral observations that reading duration is affected by length - for unfamiliar words only - have been interpreted as indirect evidence that reading unfamiliar words relies on a different, more analytical, procedure processing sequentially each subcomponent of the letter string. This hypothesis is fundamental for several models of reading such as the dual-route cascaded model, DRC, (Coltheart et al., 1993, 2001; Perry et al., 2007) and the multitrace memory model, AVC98 (Ans et al., 1998). Indeed, both models explicitly propose that the orthographic-to-phonological conversion of unfamiliar words operates analytically, graphemeby-grapheme, or syllable-by-syllable, thanks to phonological and verbal working memory processes. In contrast, both models also assume a global conversion of familiar words, within the same network, which would link directly their whole-word orthographic form to their whole-word pronunciation. Those models therefore provide a plausible explanation for the fact that reading unfamiliar words or pseudo-words takes longer than reading familiar words, a classical lexicality effect (Forster and Chambers, 1973; Glushko, 1979; Monsell et al., 1992).

Our study provides a detailed neurophysiological ground to both the DRC and ACV98 models. We confirmed that both familiar words and pseudo-words activate a common network, including Broca's area, the SMG, and ITOC. Within that network, neural responses followed a specific sequence of activation after stimulus onset an early activation of the ITOC at $200 \mathrm{~ms}$, followed by activation of Broca's area at $250 \mathrm{~ms}$, and the SMG at $340 \mathrm{~ms}$. This temporal sequence is consistent with existing models of word recognition suggesting that visual stimuli are first analyzed in terms of visual features and orthography (visual word-form) in the ITOC, 


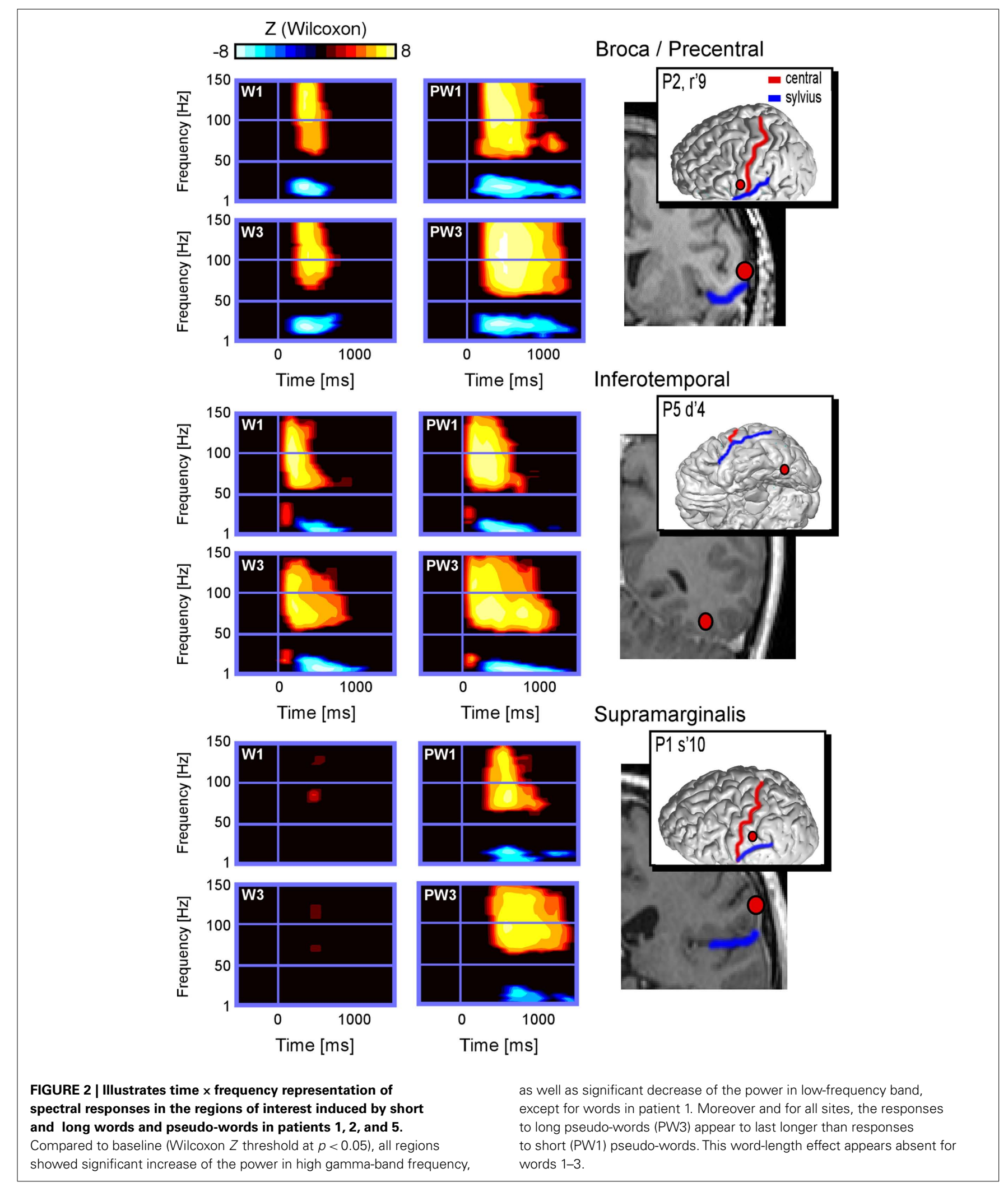

then transformed into their corresponding phonological form in Broca's area and the SMG. It is at that later stage that the differentiation between global and sequential word processing is the clearest: all neural responses recorded in Broca's area and the SMG were stronger and longer for poly-syllabic than for mono-syllabic pseudo-words, but the effect was not found for familiar words. 


\section{BROCA PRECENTRAL (patient 4) $[-64,5,19]$}

\section{INFEROTEMPORAL (patient 1) $[-53,-36,-13]$}

Word 1 vs Pseudoword 1
Word 3

vs

Pseudoword 3
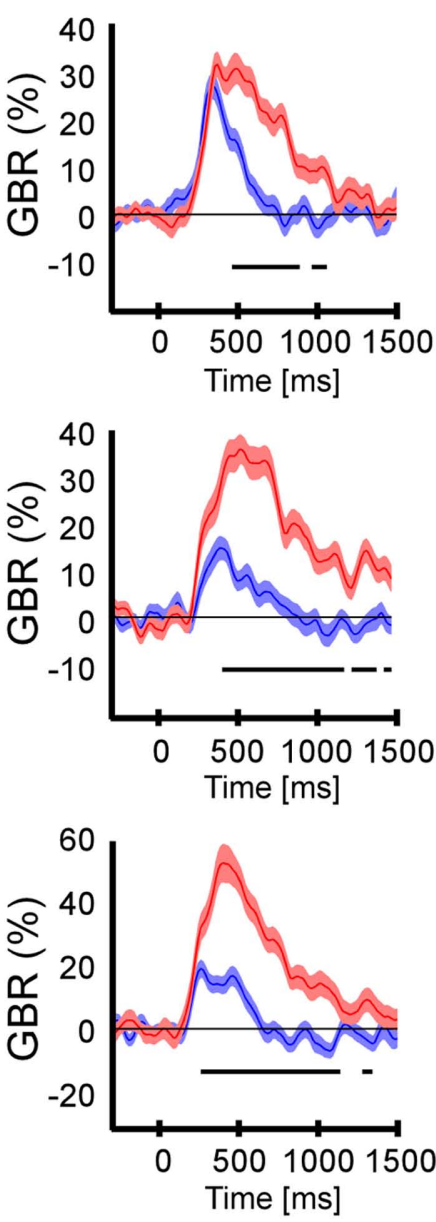
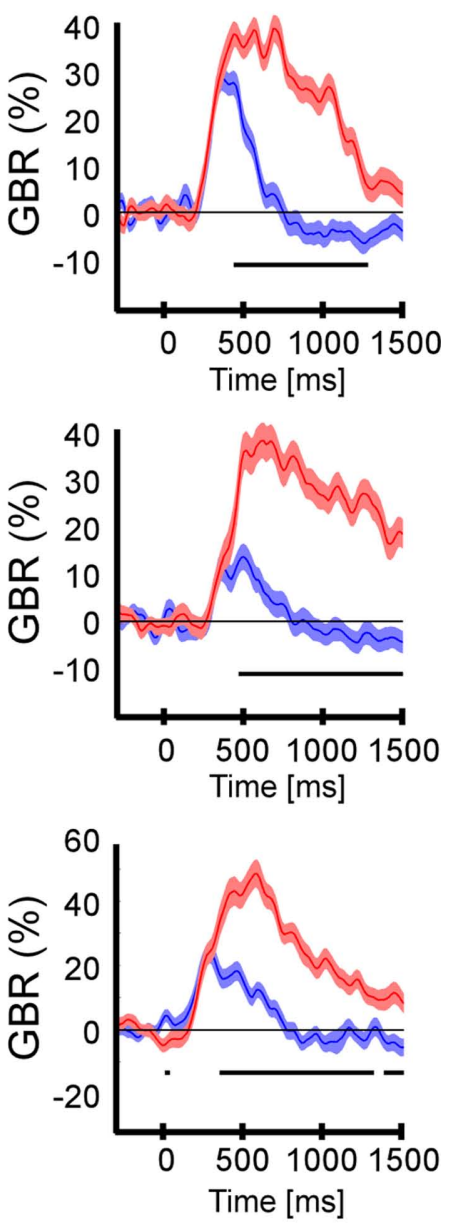

$p<0.05$

FIGURE 3 | Lexicality effect (W vs. PW) on GBR recorded in ITOC,

Broca's, and SMG in P2, P3, and P5. The black line underneath the curves indicates the time samples when the lexical conditions were significantly different ( $p<0.05$, Kruskal-Wallis, FDR corrected for multiple comparisons).
Items length induced stronger and longer GBR for pseudo-words, compared to words. Thus, across sites and for all patients, the length shows significant effect only for pseudo-words. For each region the Talairach coordinates are mentioned.
Based on the regions showing activity modulation, we suggest that the transition from sequential to global processing requires three types of processes: phonological decoding, phonological storage, and sub-vocal rehearsal. Indeed, the SMG has been frequently associated with phonological processes (Xu et al., 2001; Seghier et al., 2004; Price and Mechelli, 2005) including graphophonological conversion and verbal working memory. This region reacts stronger to pseudo-words than to words (Joubert et al., 2004; Binder et al., 2005) and has been, for that reason, associated with grapheme-to-phoneme conversion (Jobard et al., 2003; Vigneau et al., 2005; Wilson et al., 2009). Several studies have shown the involvement of the SMG during attentional reorienting (see Corbetta et al., 2008 for a review). In our study, the higher involvement of this region for long than for short pseudo-words could reflect the attentional shift from one orthographic segment to another one, during sequential reading. The SMG is also activated during verbal working memory tasks (see Owen et al., 2005 for a review) and several studies have identified that region as the locus of phonological storage within verbal working memory (Paulesu et al., 1993; Becker et al., 1999; Ravizza et al., 2004).

Evidence relating Broca's area with phonological processing is even stronger. Previous neuroimaging studies have shown 


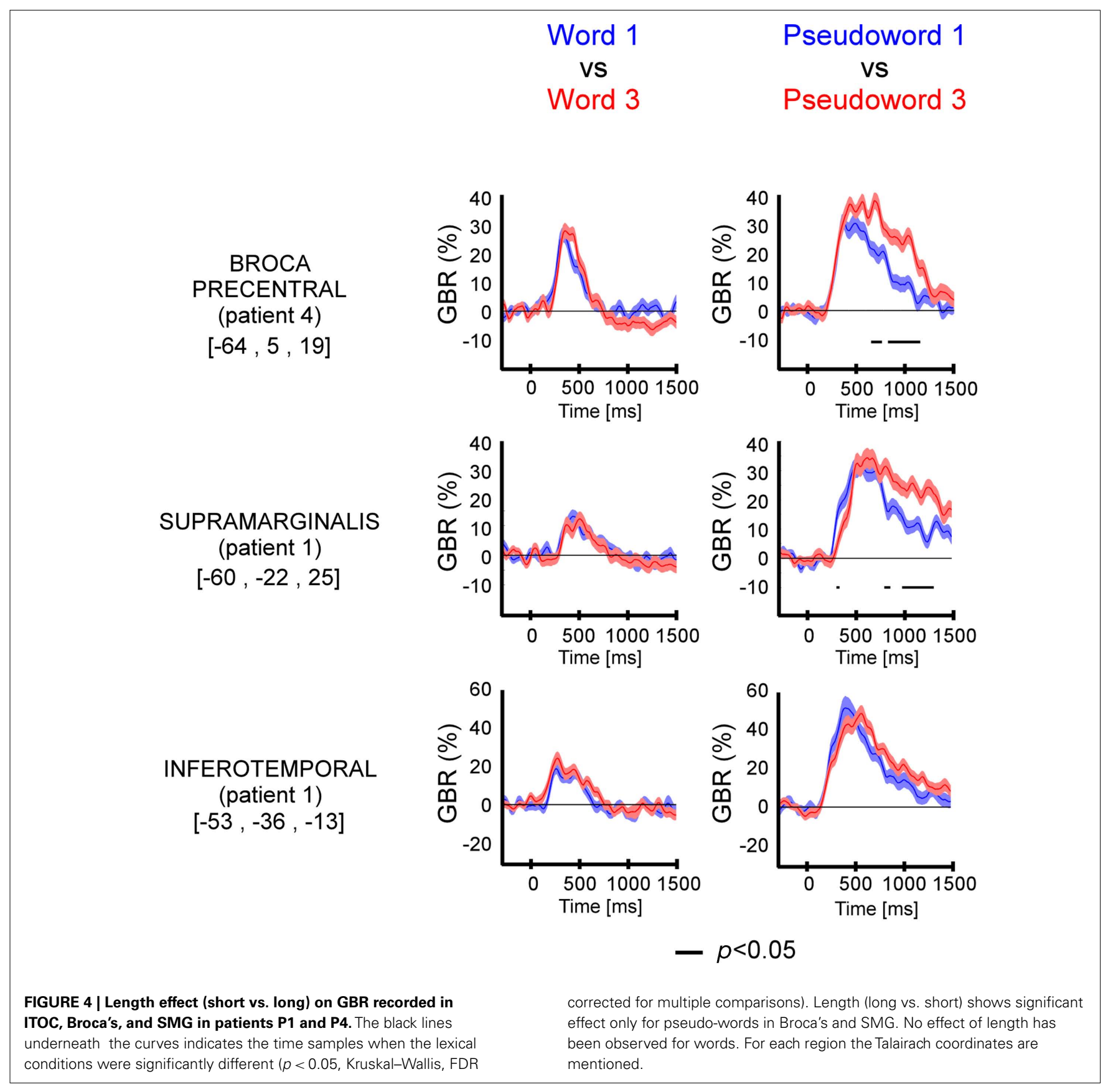

Table 2 | Activation latency recorded in each patient according to experimental conditions and recording sites.

\begin{tabular}{llllll}
\hline Region & Patient & Word 1 & Word 3 & Pseudo-word 1 & Pseudo-word 3 \\
\hline Broca (precentral) & 2 & 234 & 203 & 218 & 187 \\
Broca (precentral) & 4 & 281 & 296 & 281 & 281 \\
Supramarginalis & 1 & 343 & 359 & 312 & 359 \\
Supramarginalis & 3 & 343 & 343 & 406 & 358 \\
Inferotemporal & 1 & 250 & 203 & 234 & 218 \\
Inferotemporal & 5 & 140 & 125 & 125 & 125
\end{tabular}

For each condition, all latencies were estimated as the first time sample that elicited significant difference of the amplitude between post-stimulus gamma-band response and the average baseline amplitude [Wilcoxon paired-test comparison, corrected for multiple comparisons (FDR)]. 
that Broca's area is specifically involved in pseudo-word reading (Zatorre et al., 1996; Demonet et al., 2005; Dietz et al., 2005), phonological recoding of orthographic input strings at a sub-lexical level (Fiez and Petersen, 1998; Hagoort et al., 1999; Pammer et al., 2004), constitution of phonological forms (Mainy et al., 2007), phonological segmentation with articulatory recoding (Zatorre et al., 1996; Fiez and Petersen, 1998; Burton et al., 2000; Katzir et al., 2005), phonological manipulation (Fiez, 1997; Bookheimer, 2002; Jobard et al., 2003), sub-vocal rehearsal (Paulesu et al., 1993), and verbal working memory (Paulesu et al., 1993; Fiez, 1997; Poldrack et al., 1999, 2001; Cabeza and Nyberg, 2000; Demonet et al., 2005; Heim et al., 2005). Articulatory rehearsal involves the activation of the left precentral gyrus near the posterior part of Broca's area (Fiez et al., 2006). In addition, a recent iEEG study by Mainy et al. (2008) showed strong GBR in that region in response to words and pseudo-words but not to non-pronounceable consonant strings, which suggests that Broca's area becomes active as soon as orthographic-to-phonological conversion is required. Furthermore, another iEEG study by the same group (Mainy et al., 2007) showed strong GBR in Broca's area in direct relation with the mental rehearsal of verbal items, during a verbal working memory task. Altogether, previous neuroimaging studies provide firm evidence that Broca's area and the SMG support verbal working memory and grapho-phonological conversion. These two regions are also known to be interconnected and co-activated (Cohen et al., 1997; Duffau et al., 2003; Catani and ffytche, 2005) within a network supporting phonological and verbal working memory processes.

Our recordings from Broca's and SMG suggest that those processes operate differently on unfamiliar and familiar words. The long processing time of poly-syllabic pseudo-words suggests a sequential conversion of each orthographic unit (grapheme or syllable) into its corresponding phonological unit. The three phonological units which compose a three-syllabic pseudo-word ("sa" - "me" - "pa") would be maintained online into a verbal working memory buffer until they are assembled into the phonological representation of the whole ("samepa"). The online working memory maintaining processes need sub-vocal rehearsal (Naveh-Benjamin and Jonides, 1984; Chein and Fiez, 2001) that may involve Broca's area and SMG. Eventually, repeated reading of the same letter string would allow for a direct association between its orthographic and its phonological form, as for single syllables. The conversion from orthography to phonology would become a global process, supported by a minimal participation of

\section{REFERENCES}

Aguera, P. E., Jerbi, K., Caclin, A., and Bertrand, O. (2011). ELAN: a software package for analysis and visualization of MEG, EEG, and LFP signals. Comput. Intell. Neurosci. doi: $10.1155 / 2011 / 158970$

Andrews, S. (1997). The effect of orthographic similarity on lexical retrieval: resolving neighborhood conflicts. Psychon. Bull. Rev. 4, 439-461.

Ans, B., Carbonnel, S., and Valdois, S. (1998). A connectionist multiple-

Broca's and SMG, independently of syllabic length. Yet, the graphophonological conversion would still involve the same network, as shown in this study.

Our third region of interest, the ITOC, appears to react differently. The left ITOC, and specifically the left fusiform gyrus supporting visuo-orthographic analysis of verbal items, is considered reading-specific (Greenblatt, 1976; Warrington and Shallice, 1980; Damasio and Damasio, 1983; Henderson, 1986; Cohen et al., 2000, 2002; Leff et al., 2001; Dehaene et al., 2002; Gaillard et al., 2006). This region is involved in the very early stages of visual word recognition and specifically in orthographic processing (Cohen et al., 2000, 2002; Dehaene et al., 2002). The orthographic processing is based on the detection of familiarity (Tagamets et al., 2000; Jobard et al., 2003) and regularity (Cohen et al., 2002) in order to distinguish words from pseudo-words. Excepting one patient, our results suggest that the activity of ITOC is not modulated by length, neither for familiar nor for unfamiliar items. However, our results should be considered cautiously because they are based on single electrode recording and single effects in individual patients with disease history.

\section{CONCLUSION}

Our results show a common network of cortical regions involved for processing familiar (words) and unfamiliar (pseudo-words) verbal stimuli. This network includes Broca's area, the left SMG, and the left inferior temporo-occipital cortex. The activity of the first two regions takes longer to process unfamiliar than familiar words; their processing time increases with syllabic length for the former, but not for the latter. Given the implication of these regions in verbal working memory and phonological processes, our results strongly suggest that grapho-phonological conversion of unfamiliar words operates sequentially syllable-by-syllable, using sub-vocal rehearsal. In contrast, the conversion of familiar words operates directly at the whole-word level, independently of their length. This transition from sequential to global processing explains, at least partially, the ability of expert readers to browse texts at a pace of only several ocular fixations per second.

\section{ACKNOWLEDGMENTS}

We thank all patients for their participation, the staff of Grenoble Neurological Hospital epilepsy unit, and Dominique Hoffmann, Patricia Boschetti, Carole Chatelard, Véronique Dorlin for their support. Funding was provided by the BrainSync FP7 European Project (Grant HEALTH-F2-2008-200728).

Baciu, M. V., Watson, J. M., Maccotta, L., McDermott, K. B., Buckner, R. L., Gilliam, F. G., and Ojemann, J. G. (2005). Evaluating functional MRI procedures for assessing hemispheric language dominance in neurosurgical patients. Neuroradiology 47, 835-844.

Becker, J. T., MacAndrew, D. K., and Fiez, J. A. (1999). A comment on the functional localization of the phonological storage subsystem of working memory. Brain Cogn. 41, 27-38.
Binder, J. R., Medler, D. A., Desai, R., Conant, L. L., and Liebenthal, E. (2005). Some neurophysiological constraints on models of word naming. Neuroimage 27, 677-693.

Bookheimer, S. (2002). Functional MRI of language: new approaches to understanding the cortical organization of semantic processing. Annu. Rev. Neurosci. 25, 151-188.

Burton, M. W., Small, S. L., and Blumstein, S. E. (2000). The role of segmentation in phonological 
processing: an fMRI investigation. J. Cogn. Neurosci. 12, 679-690.

Cabeza, R., and Nyberg, L. (2000). Imaging cognition II: an empirical review of 275 PET and fMRI studies. J. Cogn. Neurosci. 12, 1-47.

Catani, M., and ffytche, D. H. (2005). The rises and falls of disconnection syndromes. Brain 128, 2224-2239.

Chein, J. M., and Fiez, J. A. (2001). Dissociation of verbal working memory system components using a delayed serial recall task. Cereb. Cortex 11, 1003-1014.

Cohen, J. D., Perlstein, W. M., Braver, T. S., Nystrom, L. E., Noll, D. C., Jonides, J., and Smith, E. E. (1997). Temporal dynamics of brain activation during a working memory task. Nature 386, 604-608.

Cohen, L., Dehaene, S., Naccache, L., Lehericy, S., Dehaene-Lambertz, G., Henaff, M. A., and Michel, F. (2000). The visual word form area: spatial and temporal characterization of an initial stage of reading in normal subjects and posterior splitbrain patients. Brain $123(\mathrm{Pt} 2)$, 291-307.

Cohen, L., Lehericy, S., Chochon, F., Lemer, C., Rivaud, S., and Dehaene, S. (2002). Language-specific tuning of visual cortex? Functional properties of the visual word form area. Brain 125, 1054-1069.

Coltheart, M., Curtis, B., Atkins, P., and Haller, M. (1993). Models of reading aloud: dual-route and paralleldistributed-processing approaches. Psychol. Rev. 100, 589-608.

Coltheart, M., Rastle, K., Perry, C., Langdon, R., and Ziegler, J. (2001). DRC: a dual route cascaded model of visual word recognition and reading aloud. Psychol. Rev. 108, 204-256.

Content, A., Mousty, P., and Radeau, M. (1990). Brulex: Une base de données lexicales informatisée pour le Français écrit et parlé [Brulex: a lexical database for written and spoken Franch]. Annee Psychol. 90, 551-566.

Corbetta, M., Patel, G., and Shulman, G. L. (2008). The reorienting system of the human brain: from environment to theory of mind. Neuron 58, 306-324.

Cornelissen, P., Tarkiainen, A., Helenius, P., and Salmelin, R. (2003). Cortical effects of shifting letter position in letter strings of varying length. J. Cogn. Neurosci. 15, 731-746.

Damasio, A. R., and Damasio, H. (1983). The anatomic basis of pure alexia. Neurology 33, 1573-1583.

Dehaene, S., Le Clec, H. G., Poline, J. B., Le Bihan, D., and Cohen, L. (2002). The visual word form area: a prelexical representation of visual words in the fusiform gyrus. Neuroreport 13, 321-325.

Demonet, J. F., Thierry, G., and Cardebat, D. (2005). Renewal of the neurophysiology of language: functional neuroimaging. Physiol. Rev. 85, 49-95.

Dietz, N. A., Jones, K. M., Gareau, L., Zeffiro, T. A., and Eden, G. F. (2005). Phonological decoding involves left posterior fusiform gyrus. Hum. Brain Mapp. 26, 81-93.

Duffau, H., Gatignol, P., Denvil, D., Lopes, M., and Capelle, L. (2003). The articulatory loop: study of the subcortical connectivity by electrostimulation. Neuroreport 14, 2005-2008.

Ferrand, L. (2000). Reading aloud polysyllabic words and nonwords: the syllabic length effect reexamined. Psychon. Bull. Rev. 7, 142-148.

Ferrand, L., and New, B. (2003). Syllabic length effects in visual word recognition and naming. Acta Psychol. (Amst.) 113, 167-183.

Fiez, J. A. (1997). Phonology, semantics, and the role of the left inferior prefrontal cortex. Hum. Brain Mapp. 5, 79-83.

Fiez, J. A., and Petersen, S. E. (1998). Neuroimaging studies of word reading. Proc. Natl. Acad. Sci. U.S.A. 95, 914-921.

Fiez, J. A., Tranel, D., Seager-Frerichs, D., and Damasio, H. (2006). Specific reading and phonological processing deficits are associated with damage to the left frontal operculum. Cortex 42, 624-643.

Forster, K. I., and Chambers, S. M. (1973). Lexical access and naming time. J. Verbal Learn. Verbal Behav. 12, 627-635.

Gaillard, R., Naccache, L., Pinel, P., Clemenceau, S., Volle, E., Hasboun, D.,Dupont, S., Baulac, M., Dehaene, S., Adam, C., and Cohen, L. (2006). Direct intracranial, FMRI and lesion evidence for the causal role of left inferotemporal cortex in reading. Neuron 50, 191-204.

Glushko, R. J. (1979). The organisation and the activation of orthographic knowledge in reading aloud. J. Exp. Psychol. Hum. Percept. Perform. 5, 674-691.

Greenblatt, S. H. (1976). Subangular alexia without agraphia or hemianopsia. Brain Lang. 3, 229-245.

Hagoort, P., Indefrey, P., Brown, C., Herzog, H., Steinmetz, H., and Seitz, R. J. (1999). The neural circuitry involved in the reading of German words and pseudowords: a PET study. J. Cogn. Neurosci. 11, 383-398.

Hauk, O., Davis, M. H., Ford, M., Pulvermuller, F., and Marslen-Wilson, W. D. (2006). The time course of visual word recognition as revealed by linear regression analysis of ERP data. Neuroimage 30, 1383-1400.

Hauk, O., and Pulvermuller, F. (2004). Effects of word length and frequency on the human event-related potential. Clin. Neurophysiol. 115, 1090-1103.

Heim, S., Alter, K., Ischebeck, A. K., Amunts, K., Eickhoff, S. B., Mohlberg, H., Zilles, K., von Camon, D. Y., and Friederici, A. D. (2005). The role of the left Brodmann's areas 44 and 45 in reading words and pseudowords. Brain. Res. Cogn. Brain Res. 25, 982-993.

Henderson, V. W. (1986). Anatomy of posterior pathways in reading: a reassessment. Brain Lang. 29, 119-133.

Jerbi, K., Ossandon, T., Hamame, C. M., Senova, S., Dalal, S. S. Jung, J., Minotti, L., Bertrand, O., Berthoz, A., Kahane, P., and Lachaux, J. P. (2009). Task-related gamma-band dynamics from an intracerebral perspective: review and implications for surface EEG and MEG. Hum. Brain Mapp. 30, 1758-1771.

Jobard, G., Crivello, F., and TzourioMazoyer, N. (2003). Evaluation of the dual route theory of reading: a metanalysis of 35 neuroimaging studies. Neuroimage 20, 693-712.

Joubert, S., Beauregard, M., Walter, N., Bourgouin, P., Beaudoin, G., Leroux, J., Karama, S., and Lecours, A. R. (2004). Neural correlates of lexical and sublexical processes in reading. Brain Lang. 89 9-20.

Juphard, A., Carbonnel, S., Ans, B. and Valdois, S. (2006). Length effect in naming and lexical decision: the multitrace memory model's account. Curr. Psychol. Lett. Behav. Brain Cogn. 19. Available at: http:// cpl.revues.org/index1005.html

Juphard, A., Carbonnel, S., and Valdois, S. (2004). Length effect in reading and lexical decision: evidence from skilled readers and a developmental dyslexic participant. Brain Cogn. 55, 332-340.

Juphard, A., Valdois, S., Carbonnel, S., Pichat, C., Ans, B., and Baciu, M. (2008). "Length effects in reading: evidence from behavioral and neuroimaging data," in Neuropsychology and Cognition of Language: Behavioural, Neuropsychological and Neuroimaging Studies of Oral and Written Language. (Trivandrum: Research SignPost), 3-21.

Katzir, T., Misra, M., and Poldrack, R. A. (2005). Imaging phonology without print: assessing the neural correlates of phonemic awareness using fMRI. Neuroimage 27, 106-115.

Kessler, B., Treiman, R., and Mullennix, J. (2002). Phonetic biases in voice key response time measurements. $J$. Mem. Lang. 47, 145-171.

Kliegl, R., Nuthmann, A., and Engbert, R. (2006). Tracking the mind during reading: the influence of past, present, and future words on fixation durations. J. Exp. Psychol. Gen. 135, 13-35.

Lachaux, J. P., Fonlupt, P., Kahane, P. Minotti, L., Hoffmann, D., Bertrand, O., and Baciu, M. (2007). Relationship between task-related gamma oscillations and BOLD signal: new insights from combined AMRI and intracranial EEG. Hum. Brain Mapp. 28, 1368-1375.

Le Van Quyen, M., Foucher, J., Lachaux, J. P., Rodriguez, E., Lutz, A., Martinerie, J., and Varela, F. J. (2001) Comparison of Hilbert transform and wavelet methods for the analysis of neuronal synchrony. J. Neurosci. Methods 111, 83-98.

Leff, A. P., Crewes, H., Plant, G. T., Scott, S. K., Kennard, C., and Wise, R. J. (2001). The functional anatomy of single-word reading in patients with hemianopic and pure alexia. Brain 124, 510-521.

Mainy, N., Jung, J., Baciu, M., Kahane, P., Schoendorff, B., Minotti, L.,Hoffmann, D., Bertrand, O., and Lachaux, J. P. (2008). Cortical dynamics of word recognition. Hum. Brain Mapp. 29, 1215-1230.

Mainy, N., Kahane, P., Minotti, L., Hoffmann, D., Bertrand, O., and Lachaux, J. P. (2007). Neural correlates of consolidation in working memory. Hum. Brain Mapp. 28, 183-193.

Mason, M. (1978). From print to sound in mature readers as a function of reader ability and two forms of orthographic regularity. Mem. Cognit. 6, 568-581.

Monsell, S., Patterson, K. E., Graham, A., Hughes, C. H., and Milroy, R. (1992). Lexical and sublexical translation of spelling to sound: strategic anticipation of lexical status. J. Exp. Psychol. Learn Mem. Cogn. $18,452$.

Naveh-Benjamin, M., and Jonides, J. (1984). Maintenance rehearsal: a two-component analysis. J. Exp. Psychol. Learn Mem. Cogn. 10, 369-385.

Ojemann, G. A., Fried, I., and Lettich, E. (1989). Electrocorticographic (ECoG) correlates of language. I. Desynchronization in temporal language cortex during object naming. Electroencephalogr. Clin. Neurophysiol. 73, 453-463. 
Owen, A. M., McMillan, K. M., Laird, A. R., and Bullmore, E. (2005). Nback working memory paradigm: a meta-analysis of normative functional neuroimaging studies. Hum. Brain. Mapp. 25, 46-59.

Pammer, K., Hansen, P. C., Kringelbach, M. L., Holliday, I., Barnes, G., Hillebrand, A., Singh, K. D., and Cornelissen, P. L. (2004). Visual word recognition: the first half second. Neuroimage 22, 1819-1825.

Paulesu, E., Frith, C. D., and Frackowiak, R. S. (1993). The neural correlates of the verbal component of working memory. Nature 362, 342-345.

Perry, C., Ziegler, J. C., and Zorzi, M. (2007). Nested incremental modeling in the development of computational theories: the CDP+ model of reading aloud. Psychol. Rev. 114, 273-315.

Poldrack, R. A., Temple, E., Protopapas, A., Nagarajan, S., Tallal, P., Merzenich, M., and Gabrieli, J. D. (2001). Relations between the neural bases of dynamic auditory processing and phonological processing: evidence from fMRI. J. Cogn. Neurosci. 13, 687-697.

Poldrack, R. A., Wagner, A. D., Prull, M. W., Desmond, J. E., Glover, G. H., and Gabrieli, J. D. (1999). Functional specialization for semantic and phonological processing in the left inferior prefrontal cortex. $\mathrm{Neu}$ roimage $10,15-35$.

Price, C. J., and Mechelli, A. (2005). Reading, and reading disturbance. Curr. Opin. Neurobiol. 15, 231-238.

Ravizza, S. M., Delgado, M. R., Chein, J. M., Becker, J. T., and Fiez, J. A. (2004). Functional dissociations within the inferior parietal cortex in verbal working memory. Neuroimage 22, 562-573.
Ray, S., and Maunsell, J. H. (2011). Different origins of gamma rhythm and high-gamma activity in macaque visual cortex. PLoS Biol. 9, e1000610. doi: 10.1371/journal.pbio. 1000610

Schendan, H. E., Ganis, G., and Kutas, M. (1998). Neurophysiological evidence for visual perceptual categorization of words and faces within $150 \mathrm{~ms}$. Psychophysiology 35, 240-251.

Seghier, M. L., Lazeyras, F., Pegna, A. J., Annoni, J. M., Zimine, I., Mayer, E., Michel, C. M., and Khateb, A. (2004). Variability of fMRI activation during a phonological and semantic language task in healthy subjects. Hum. Brain Mapp. 23, 140-155.

Tagamets, M. A., Novick, J. M. Chalmers, M. L., and Friedman, R. B. (2000). A parametric approach to orthographic processing in the brain: an fMRI study. J. Cogn. Neurosci. 12, 281-297.

Talairach, J., and Tournoux, P. (1988). Co-Planar Stereotaxic Atlas of the Human Brain: 3-Dimensional Proportional System: An Approach to Cerebral Imaging. New York: Thieme.

Tallon-Baudry, C., Bertrand, O., Delpuech, C., and Permier, J. (1997). Oscillatory gamma-band $\quad(30-70$ $\mathrm{Hz}$ ) activity induced by a visual search task in humans. J. Neurosci. 17, 722-734

Valdois, S., Carbonnel, S., Juphard, A., Baciu, M., Ans, B., Peyrin, C., and Segebarth, C. (2006). Polysyllabic pseudo-word processing in reading and lexical decision: converging evidence from behavioral data, connectionist simulations and functional MRI. Brain Res. 1085, 149-162.
Vidal, J. R., Ossandon, T. S, Jerbi, K. Dalal, S. S., Minotti, L., Ryvlin, P., Kahane, P., and Lachaux, J.-P. (2010). Category-specific visual responses: an intracranial study comparing gamma, beta, alpha and ERP response selectivity. Front. Hum. Neurosci. 4:195. doi 10.3389/fnhum.2010.00195

Vigneau, M., Beaucousin, V., Herve, P. Y., Duffau, H., Crivello, F., Houde, O.,Mazoyer, B., and Tzourio-Mazoyer, N. (2006). Metaanalyzing left hemisphere language areas: phonology, semantics, and sentence processing. Neuroimage 30, 1414-1432.

Vigneau, M., Jobard, G., Mazoyer, B., and Tzourio-Mazoyer, N. (2005). Word and non-word reading: what role for the visual word form area? Neuroimage 27, 694-705.

Warrington, E. K., and Shallice, T. (1980). Word-form dyslexia. Brain 103, 99-112.

Weekes, B. S. (1997). Differential effects of number of letters on word and nonword naming latency. Q. J. Exp. Psychol. A 50, 439-456.

Wilson, S. M., Isenberg, A. L., and Hickok, G. (2009). Neural correlates of word production stages delineated by parametric modulation of psycholinguistic variables. Hum. Brain Mapp. 30, 3596-3608.

Wyart, V., and Tallon-Baudry, C. (2008). Neural dissociation between visual awareness and spatial attention. $J$. Neurosci. 28, 2667-2679.

Wydell, T. N., Vuorinen, T., Helenius P., and Salmelin, R. (2003). Neural correlates of letter-string length and lexicality during reading in a regular orthography. J. Cogn. Neurosci. 15, 1052-1062.
Xu, B., Grafman, J., Gaillard, W. D., Ishii, K., Vega-Bermudez, F., Pietrini, P., Reeves-Tyer, P., DiCamillo, P., and Theodore, W. (2001). Conjoint and extended neural networks for the computation of speech codes: the neural basis of selective impairment in reading words and pseudowords. Cereb. Cortex 11, 267-277.

Zatorre, R. J., Meyer, E., Gjedde, A., and Evans, A. C. (1996). PET studies of phonetic processing of speech: review, replication, and reanalysis. Cereb. Cortex 6, 21-30.

Conflict of Interest Statement: The authors declare that the research was conducted in the absence of any commercial or financial relationships that could be construed as a potential conflict of interest.

Received: 30 May 2011; paper pending published: 01 July 2011; accepted: 31 August 2011; published online: 20 September 2011.

Citation: Juphard A, Vidal JR, PerroneBertolotti M, Minotti L, Kahane $P$, Lachaux J-P and Baciu M (2011) Direct evidence for two different neural mechanisms for reading familiar and unfamiliar words: an intra-cerebral EEG study. Front. Hum. Neurosci. 5:101. doi: 10.3389/fnhum.2011.00101

Copyright (c) 2011 Juphard, Vidal, Perrone-Bertolotti, Minotti, Kahane, Lachaux and Baciu. This is an openaccess article subject to a non-exclusive license between the authors and Frontiers Media SA, which permits use, distribution and reproduction in other forums, provided the original authors and source are credited and other Frontiers conditions are complied with. 


\section{APPENDIX}

Table A1 |The table resumes several demographic data of patients P1-P5: sex (male, M; female, F); age (years old); handedness (H; right-handed, R); verbal scores (assessed with WAIS-III) showing either verbal IQ (VIO) or verbal comprehension index (VCI), according to their availability.

\begin{tabular}{lllll}
\hline Patients & Sex & Age & H & Verbal level \\
\hline P1 & M & 50 & $\mathrm{R}$ & $\mathrm{VIQ}=96$ \\
$\mathrm{VCl}=101$ & $\mathrm{R}$ & $\mathrm{VIQ}=98$ \\
P2 & $\mathrm{F}$ & 38 & $\mathrm{R}$ & $\mathrm{VIQ}=96$ \\
P3 & & & $\mathrm{R}$ & $\mathrm{VCl}=91$ \\
P4 & $\mathrm{F}$ & 33 & $\mathrm{R}$ & $\mathrm{VCl}=81$ \\
P5 & F & 55 & 4 \\
\hline
\end{tabular}


Word 1

vs

Word 3

BROCA

PRECENTRAL

(patient 2)

$[-59,5.7,12]$
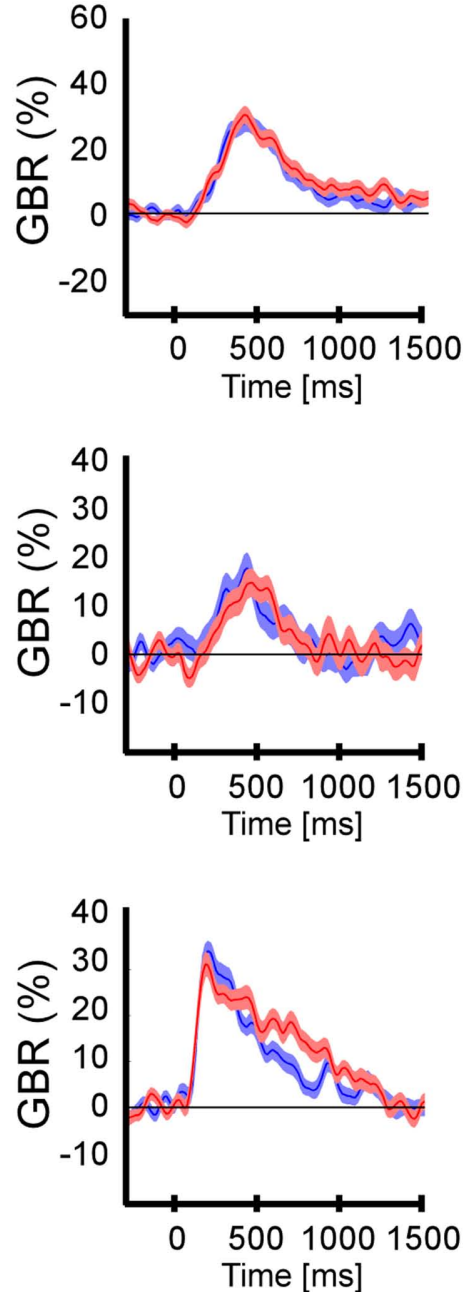

FIGURE A1 | Lexicality effect (word vs. pseudo-word) on gamma-band responses (GBR) recorded in ITOC, Broca's, and SMG in patients $\mathbf{P 2}, \mathbf{P 3}$, and $\mathbf{P 5}$. The black line underneath the curves indicates time samples when the two conditions were significantly different ( $p<0.05$, Kruskal-Wallis, FDR corrected for
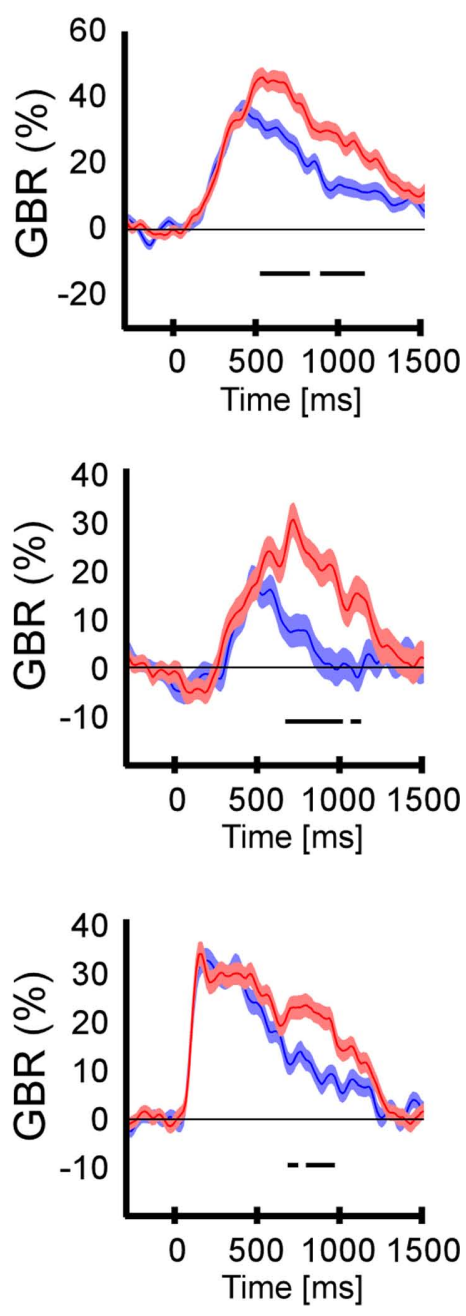

$-p<0.05$

\section{Pseudoword 1 vs \\ Pseudoword 3}




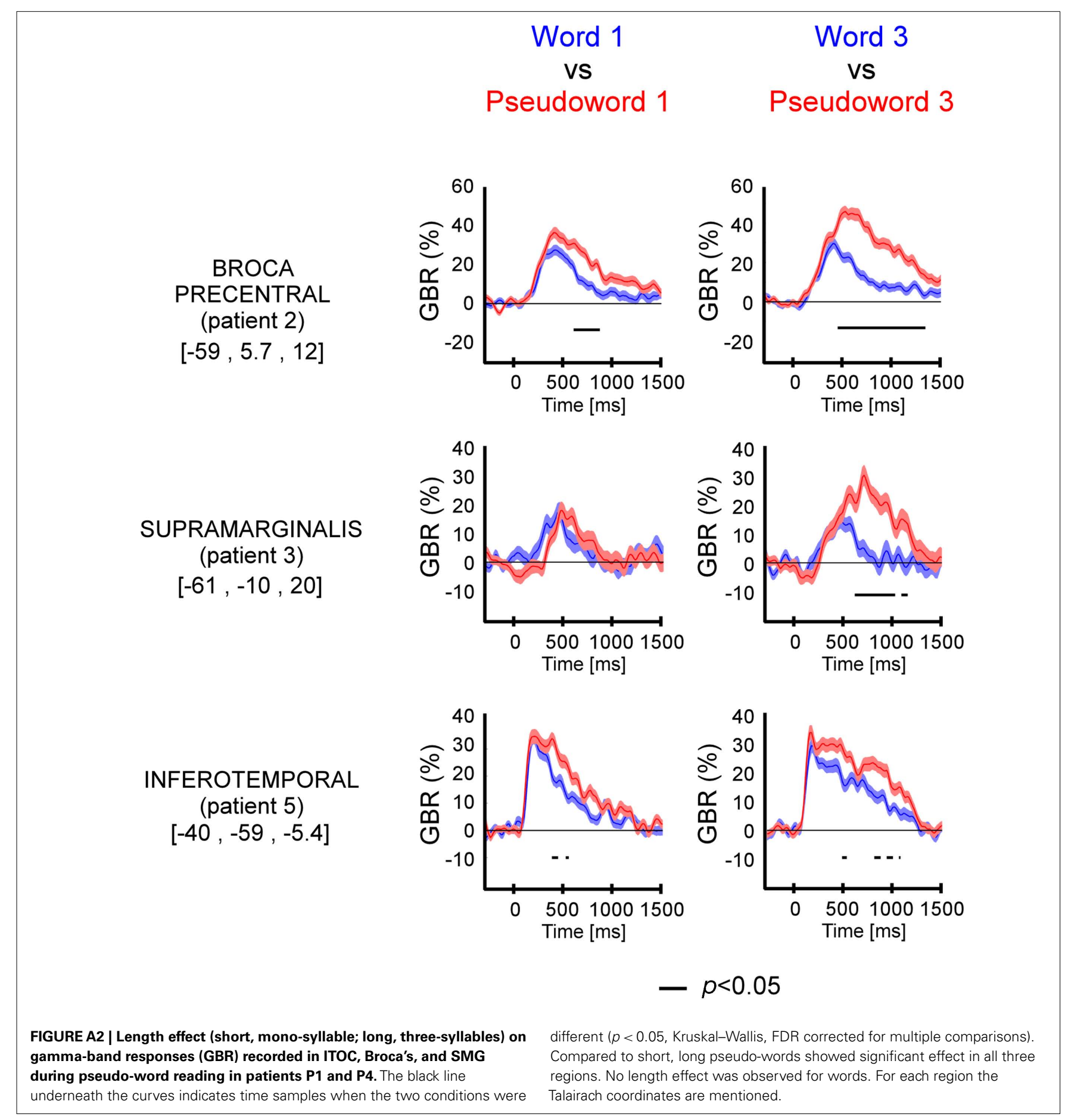




\section{Hilbert transform}

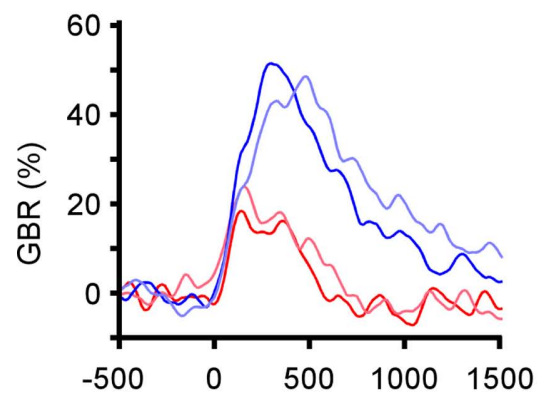

Time [ms]

FIGURE A3 | Equivalent gamma-band $(50-150 \mathrm{~Hz})$ response estimates in four experimental conditions. Left panel: gamma amplitude response assessed with Hilbert transform. Right panel:

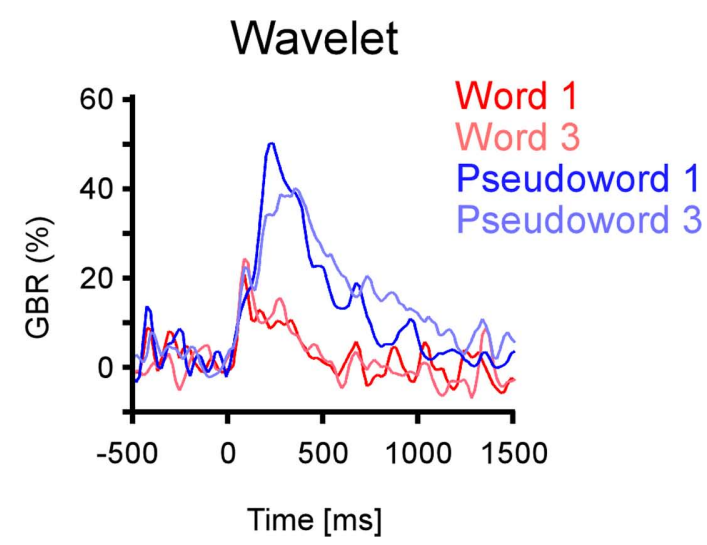

gamma power response estimated with Morlet wavelets. The electrode is located in inferior temporal cortex from patient 1 (Talairach coordinates $[-53-36-13])$.

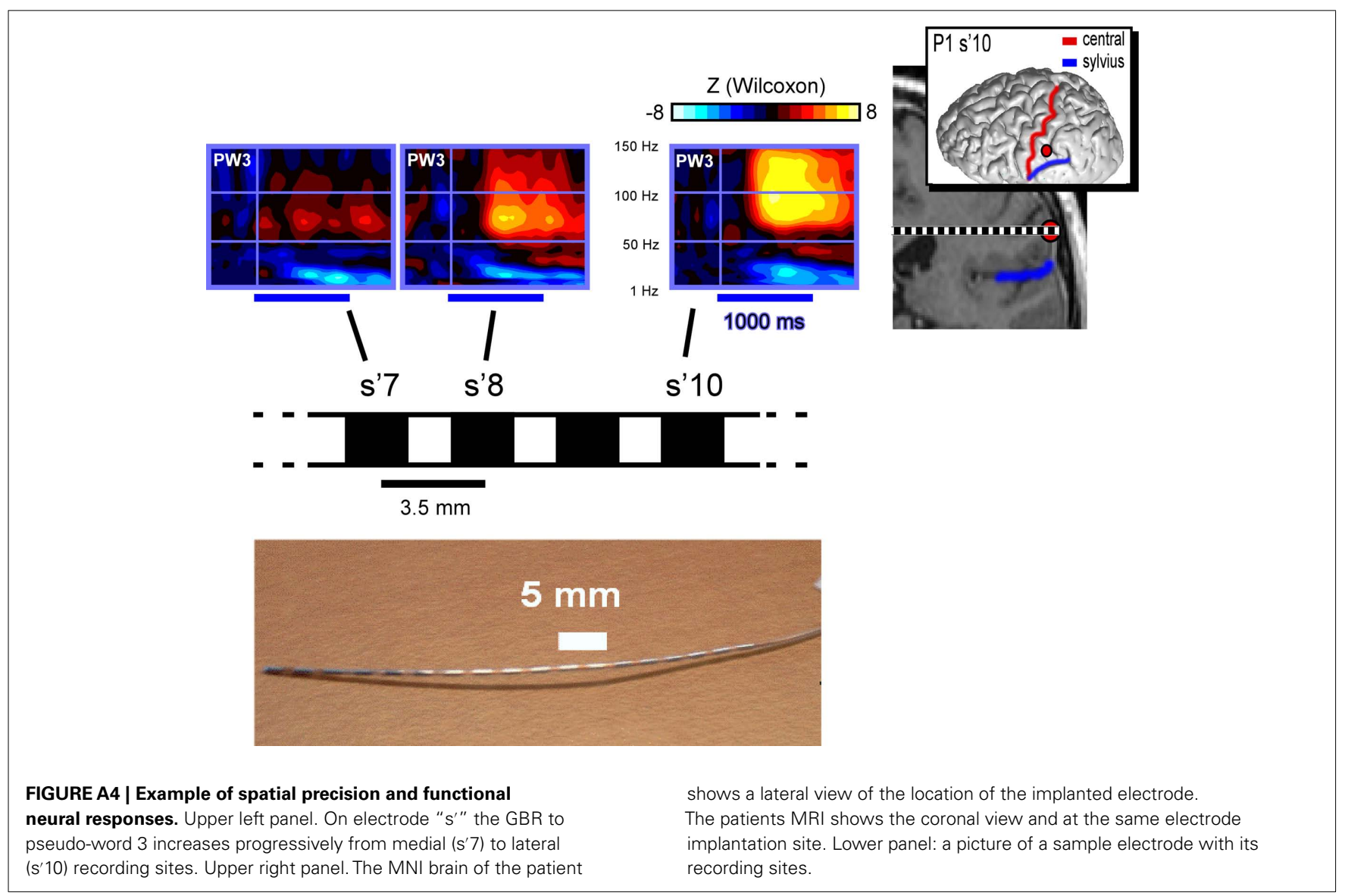




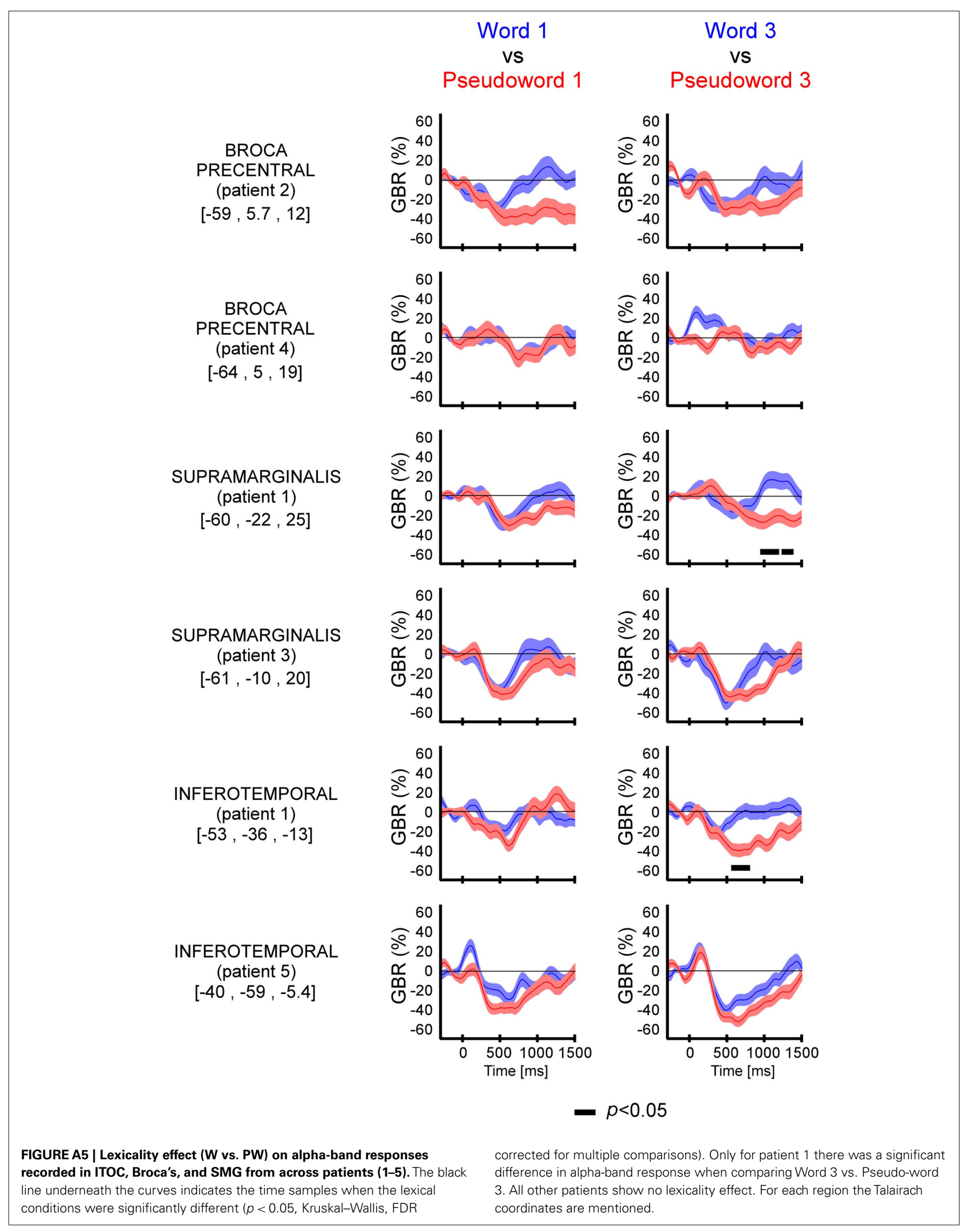




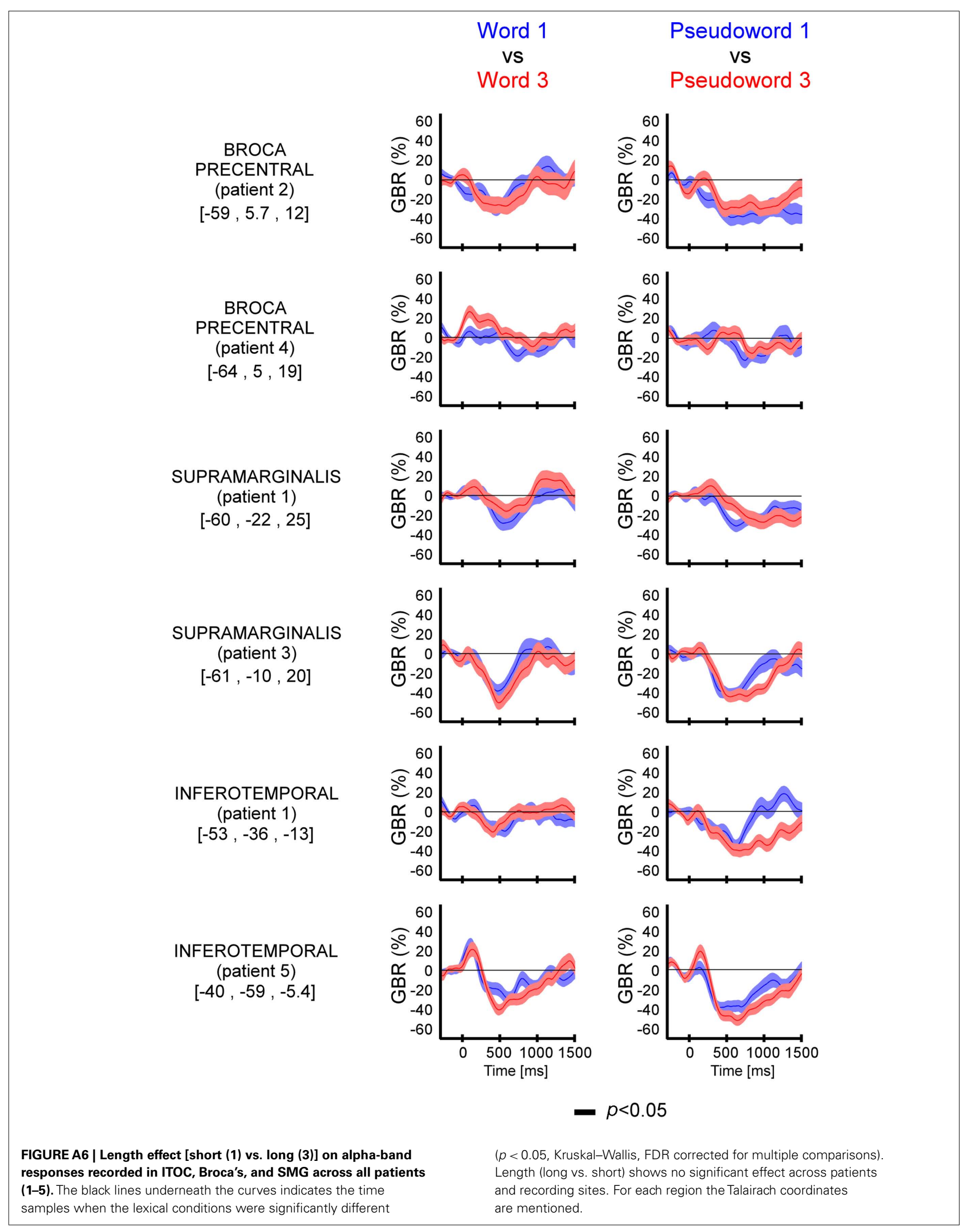




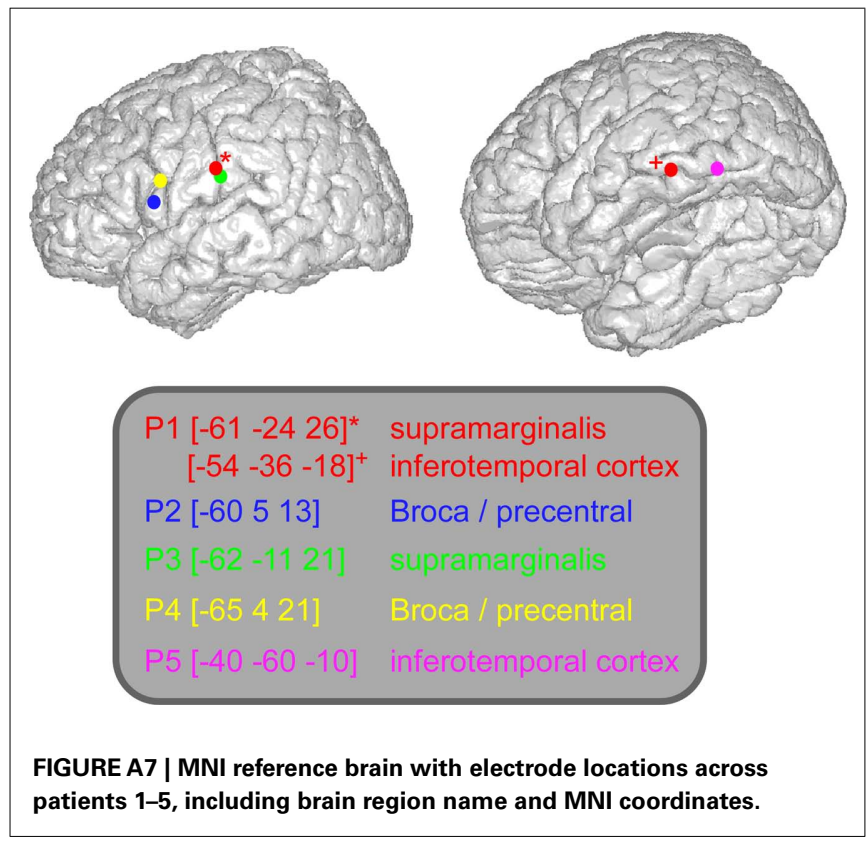

